\title{
EL NOCTURNO Y LAS INTERROGANTES DE LA REFLEXIÓN DIVINA EN MILAGRO ABIERTO DE JORGE DEBRAVO ${ }^{1}$
}

\author{
Jorge Chen Sham
}

\begin{abstract}
RESUMEN
En su fundamental poemario, Milagro abierto (1969), Jorge Debravo se dirige con un grito desolador y lastimero a la divinidad y lo hace, principalmente, en la noche. Bajo la modalidad temática del nocturno religioso, el poeta costarricense potencializa y subraya esa constante en que la noche convoca y refuerza los lazos humanos y espirituales, con lo cual se explicarían las razones por las cuales Debravo principalmente sigue cultivando el nocturno. Llama la atención la impronta que la búsqueda de la trascendencia adquiere en la propuesta del poeta costarricense en ese diálogo estimulante con las vanguardias poéticas hispanas, sobre todo, en lo que se refiere a Miguel Hernández, César Vallejo y Pablo Neruda.

Palabras clave: Debravo-Jorge, poesía costarricense, nocturno, idea de Dios, Milagro abierto.
\end{abstract}

\begin{abstract}
In his collection of poetry, Milagro Abiero (1969), Jorge Debravo directs at us a devastating and piteous cry at the divinity and what it does, mainly, at night. Under the thematic modality of the religious nocturne, the Costa Rican poet potentializes and emphasizes that constant in which the night summons and strengthens human and spiritual bonds, which would explain the reasons for which Debravo continues cultivating the nocturne. He calls to our attention the impression that the search for transcendence acquires in the work of the Costa Rican poet in that stimulating dialogue with those in the Hispanic poetic vanguard, mainly, Miguel Hernández, César Vallejo and Pablo Neruda.
\end{abstract}

Key Words: Debravo-Jorge, costarican poetry, nocturne, Good's idea, Milagro abierto.

El nocturno es un modo de composición al que el Romanticismo dará genuina madurez, con ese privilegio que el sueño y el vuelo nocturnos producen en una poesía que otorga una gran conciencia al desarrollo de la vida interior y al proceso de introspección por ellos desencadenados. Para que se despliegue esta revelación y se mire diferencial y radicalmente al individuo y la materia, se impone un tiempo preferencial en el que la ensoñación y la

Dr. Jorge Chen Sham. Profesor de la Escuela de Filología, Lingüística y Literatura. Universidad de Costa Rica. Correo electrónico: jorgechsh@yahoo.com

Recepción: 03- 01- 2012

Aceptación: 01- 02- 2012 
imaginación deben ejercitarse. No es casual, como ha demostrado Albert Béguin (1993) para el romanticismo alemán, la preponderancia que los estudios psicológicos sobre el sueño ganarán en el último tercio del siglo XVIII en Europa, pues la visión onírica conducirá a la correlación entre mecanismos poéticos y el perfeccionamiento de la vida psíquica del artista. Ese crecimiento espiritual del poeta solo es posible si dejamos esa realidad cotidiana y apariencial para perfeccionarnos en la vida interior, restitutiva y reintegrativa, con nuestro propio yo, porque, "para ellos [los románticos], son precisamente el sueño y los demás estados 'subjetivos' los que nos hacen descender en nosotros mismos y encontrar esa parte nuestra que 'es más nosotros mismos' que nuestra misma conciencia" (Béguin 1993: 29). La noche -también las transiciones del día a la noche (el crepúsculo) o viceversa (la madrugada)-, se convertirá en el tiempo ideal para llevar a cabo estas transformaciones del espíritu; su forma poética más completa para interpretar este estado de conciencia intensificada o de funcionamiento perturbador será el nocturno, en donde la imaginación y la ensoñación se llevarán al límite en su confrontación con los grandes fantasmas del poeta: la existencia, la trascendencia divina, el amor.

En el caso de Jorge Debravo y su fundamental poemario, Milagro abierto (1969), analizaremos la modalidad temática del nocturno religioso en la que la imagen de la divinidad se potencializa y se subraya esa constante en que la noche convoca y refuerza los lazos humanos y espirituales, con lo cual se explicarían las razones por las cuales Debravo sigue cultivando el nocturno. Llama la atención la impronta que la búsqueda de la trascendencia posee en la propuesta del poeta costarricense. Precisamente, M. H. Abrams (1992), señala la radicalidad romántica del pensamiento religioso (en su sentido etimológico más prístino, de esa necesidad de búsqueda de la trascendencia y de comulgar con una fuerza absoluta). Sus cuestionamientos se hallan enraizados en esa búsqueda del lugar del ser humano en la naturaleza, su reconciliación con ella y la divinidad; el Romanticismo pretende "encontrar el camino de reintegración que restaure su unidad consigo mismo, su comunidad con sus prójimos y su compañerismo con un mundo exterior ajeno y hostil" (Abrams 1992: 147) y, para ello, la dimensión nocturna en la que el poeta se enfrenta con sus propios fantasmas y dudas existenciales, las cuales se hacen ostensibles en este poemario. Esta peculiaridad de la condición humana, perturbada y enajenada, potencializa y multiplica el valor de la experiencia de angustia y rebeldía ante la divinidad, pues para el Romanticismo el hombre intenta recobrar el "paraíso perdido" que le fue arrebatado:

[...] y el Hombre puede prever fragmentariamente su destino mortal, su miseria, su rebelión, su triste existencia solitaria, a lo que su Espíritu puede oponer su esencia a la altura de todos los dolores, una voluntad firme y una conciencia profunda que, incluso en la tortura, puede descubrir su recompensa concentrada en sí misma, pues triunfa cuando osa desafiar y porque hace de la Muerte una victoria. (Aguiar e Silva 1979: 333)

Esa "conciencia profunda" es la que conduce en Jorge Debravo a una concepción pesimista de la existencia. Veamos el poema "Angustia":

\footnotetext{
A veces las palabras son como maldiciones: penetran como púas y se quedan pegadas a los cueros del alma.

Todo es como si Dios nos hubiera vendido y nos llevaran lejos, con los ojos vendados. 
Poema abrumador desde el punto de vista de la interpelación a la divinidad, agobiante por las imágenes de dolor en esos instrumentos punzo-cortantes que penetran en el cuerpo y en el alma del yo lírico, tenemos aquí la clave de la condición humana frente a la divinidad: la idea de un Dios absurdo y que ha dejado al hombre a su propio arbitrio, que lo ha expulsado de su paraíso para que siga su ruta "con los ojos vendados" subraya la desorientación y la incertidumbre. Implícitamente, surge el motivo del camino gracias al verbo "llevar"; el hombre es conducido aquí sin saber su norte y su guía, lo cual genera su frustración y angustia. Como dije más arriba, tres imágenes imponen los semas de dolor intenso y los tres tienen que ver con las acciones de producir sufrimiento y de cortar/perforar el cuerpo:

penetran como púas (v. 2)

como si le clavaran/ un hueso de demonio (vv. 6-7)

y la muerte viniera, con un cuchillo negro (v. 8)

Es más, recordemos que la imagen de la muerte comparada con el "cuchillo" se debe al poeta Miguel Hernández, quien en el primer poema de su fundamental El rayo que no cesa (1936), la presenta de esta manera:

Un carnívoro cuchillo,/ de ala dulce y homicida

sostiene un vuelo y un brillo/alrededor de mi vida.

Rayo de metal crispado/ fulgentemente caído,

picotea mi costado/ y hace en él un triste nido. (Hernández 2002: 73)

El "carnívoro cuchillo" (v.1), es decir, que come la carne, tiene la fuerza para hundirse, para "picotear", en una que podemos catalogar de acción violenta y contundente de ensañamiento contra el ser humano. En la propuesta debraviana, esa muerte que duele en el cuerpo como en el alma es la que, sin duda, hará de la trascendencia divina una obligación en sus esquemas mentales e impregnará las concepciones artísticas acerca del mundo y del poder de la Poesía.

Pero, por otro lado, devolviéndonos al poema "Angustia", veamos sus dos últimos versos, en los que se expresa la condición espacio-temporal en la que se desarrolla tal reflexión en la diferencia entre despierto/dormido, pues la expresión "dormir despierto" que ya se acuñara en el barroco español, cobra estatuto ontológico en la condición del soñador romántico, de aquel que siente el sueño nocturno como la fuente de su evasión y de su escape, pero que se encuentra en estado de vigilia permanente: "y la muerte viniera, con un cuchillo negro,/ degollando a los pocos que dormimos despiertos" (vv. 8-9). La meditación sobre la muerte cobra todo su sentido para que se subraye esa conciencia radical de quien neutraliza lo diurno/ lo nocturno, propio de esos seres privilegiados y atormentados a la vez. Muerte y Dios son los dos elementos que se convocan en la noche interior en procura de ese conocimiento revelador de la trascendencia.

A este respecto, Abrams (1992) señala cuatro claves para comprender la búsqueda romántica de la divinidad, el cual nos permitirá observar el estadio en el que se encuentra la de Jorge Debravo, tal y como se esboza en Milagro abierto.

a) Es un sistema en movimiento, de manera que toda comprensión empieza desde adentro y, por lo tanto, es "autogenerativo, omnicomprensivo y autocontenido" (1992: 169). Todo lo que implica el universo debe regresar, por inmanencia, al lugar desde donde procede. Es un proceso dinámico, empujado y redinamizado por una fuerza interna, el yo, que relaciona en devenir, en movimiento y, por lo tanto, funciona en progresión, en dialéctica con el exterior para preguntarse sobre el origen y el ser. 
b) Este movimiento dialéctico conduce a una "teología inmanente"(de nuevo insistimos en la etimología de la palabra, un pensamiento sobre Dios), pues como plantea Hegel, "[...] la evolución dialéctica de la razón sistemática en la filosofía tiene su correlativo fenomenal y temporal en el proceso del universo físico, y en el curso de toda la experiencia humana y toda historia humana" (1992: 173); razón por la cual el filósofo/ poeta se preguntará, esencialmente, por la condición del ser humano y el accionar de la trascendencia en su devenir.

c) La unidad perdida/recobrada en cuanto marco de este diseño teológico que conducirá a la unidad de la conciencia reintegrativa con el cosmos y con la divinidad. El espíritu enaltecedor del artista imaginará esos escenarios de unidad recobrada y la poesía nos iluminará en cuanto a ese camino de perfección y de iniciación que se traza en la filosofía, pues nos hace tomar conciencia, reflexionar en dos dimensiones, cognitiva y moral: "La primera se manifiesta en una escisión entre su espíritu y la naturaleza exterior, y la segunda se manifiesta en una escisión en el interior de la naturaleza del hombre mismo. En su dimensión cognitiva, esa división consiste en la pérdida de la unidad original del espíritu y la naturaleza [...]. En su dimensión moral, consiste en la pérdida de la unidad original del espíritu consigo mismo [...]” (1992: 176).

d) La búsqueda del progreso y la unidad es el comienzo y meta de todo proceso de mejoramiento del ser humano. La aspiración al absoluto y a la divinidad serían las consecuencias de esta búsqueda que redirecciona la existencia, de tal modo que en el retorno al origen se alcanza en la consideración de ese proceso llevado a cabo y gracias al cual se da cuenta el ser humano de su progreso; se trata de una unidad depurativa y de condición más alta porque incorpora los obstáculos y las diferencias, que son parte de ese proceso de mejoramiento: “[...] es su aspiración a una armonía e integridad mucho más alta que la unidad que ha perdido. Y es más alta [...], no sólo porque preserva la diversificación y la individualidad, sino también porque, en lugar de ser una condición que ha sido simplemente dada al hombre, es una condición que tenemos que ganarnos mediante el esfuerzo incesante a lo largo de un camino" (1992: 179).

Las demandas afectivas y cognitivas que embargan al yo poético en Milagro abierto hacen que la búsqueda siga interpelando en una modalidad genérica que se presta para desplegar la función expresiva de las emociones en la noche: "El sueño nocturno es la fuente en que se alimenta la poesía" (Béguin 1993: 414) y, de esta manera, podemos iniciar su recorrido por Jorge Debravo y observar hasta dónde nos permite llegar este poemario en la búsqueda de la trascendencia.

Iniciemos, pues, este camino por esa interpelación de la "noche oscura"2, que conduce al yo lírico a salirse de sí mismo y a expresar en la desnudez y en la solitud que experimenta una desazón y un abandono de la divinidad; tal planteamiento es válido en la sección "Bestiecillas plásticas", de la cual analizaremos una serie de poemas ${ }^{3}$. Bajo el trasfondo de una canción de cuna de eco lorquiano en el motivo de la luna y del niño ${ }^{4}$, se evidencia la ausencia de la divinidad. Aquí "luna” y "corazón” entrarán en una sistemática especular como explica Ma. Isabel López Martínez:

Dios no está.

Sólo la luna

rueda como un gran balón.

La noche es una honda cuna.

Un niño mi corazón... 


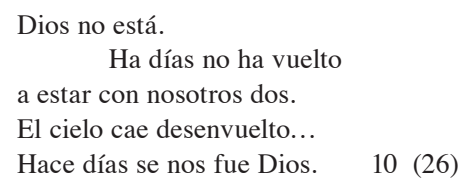

Estamos ante una poesía de una sencillez y economía estilísticas insuperables dentro de una simetría estrófica y una rima del tipo ABAB; la repetición del estribillo (“Dios no está”) logra crear esa musicalidad que el verso breve provoca para producir un ambiente de recogimiento y de meditación. Se establece un paralelismo entre el paisaje de la noche en el que "luna" (v. 2) y "cuna" (v. 4) desarrollan el motivo de la canción de cuna creando la atmósfera necesaria al nocturno; con el verbo rodar, se asegura el movimiento de "luna" y el efecto de la temporalidad es inmediato, mientras que en la comparación de la "noche" con una "honda cuna" se logra la relación metonímica con el arrullo y la posibilidad de descanso, al tiempo que la segunda comparación del verso 5 sugiere el afecto y la ternura anheladas por parte del yo lírico. En la segunda estrofa, por su parte, se subraya lo que el estribillo enuncia, la ausencia de la divinidad, en un escenario en el que su regreso es incierto y el vacío que deja en la relación de pareja (vv. 6-7) es harto evidente, lo cual provoca la prosopeya del verso 9, para los dos amantes que contemplan el horizonte estelar ("El cielo cae desenvuelto...”). La inmensidad de la noche es apabullante, con lo cual se revela el mecanismo de catarsis, que Christine Bridges plantea para el género de las canciones de cuna: "La canción puede empezar con una fórmula expresando cariño hacia el niño y luego puede continuar expresando frustración y enojo, expresión que muchas veces enlaza el mundo de la realidad con el del sueño" (1999: 108). De esta manera, en la fusión de las dos estrofas, la ternura y afecto desembocan en la acentuación de la frustración que embarga al yo lírico ante la orfandad divina. Su origen podría estar en Los heraldos negros (1918) de César Vallejos, explícitamente del inicio del poema "Dios", con lo cual establecemos una relación intertextual, reconocida por críticos y poetas $^{6}$, pero nunca repertoriada en sus imágenes y lazos textuales:

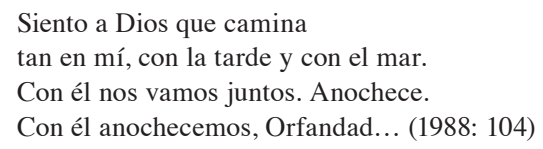

Por otra parte, Jorge Debravo continúa con este sentimiento disfórico en otro poema construido a partir del apóstrofe lírico, revelando así el espíritu tormentoso y afligido del yo poético en esa interpelación hacia la divinidad:

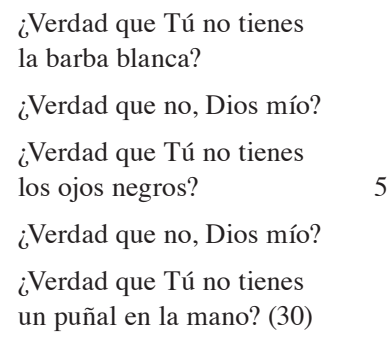

Una vez más la economía expresiva se logra en la repetición anafórica de la frase “¿Verdad que...?" y del vocativo "Dios mío", dentro de un contexto de súplica y de imprecación lastimera. En este sentido, el hablante lírico se dirige a la divinidad para interrogarlo. En la imaginería popular católica, la representación antropofórmica de la divinidad en la figura de Dios Padre se encuentra 
consolidada en la Santísima Trinidad, en la que "la barba blanca" (v. 2) y "los ojos negros" (v. 5), por cierto profundos y escrutadores, son los rasgos característicos de su fisionomía. Sin embargo, el retrato se cierra con un desenlace inesperado, al subrayar un elemento atípico en su configuración, pero que remite a esa concepción desgarradora y pesimista de la existencia; de nuevo un instrumento punzo-cortante cobra relieve para subrayar ese sufrimiento del ser humano y que se vuelve reclamo a la divinidad, tal y como sucede en el inicio de "Los heraldos negros" de Vallejo:

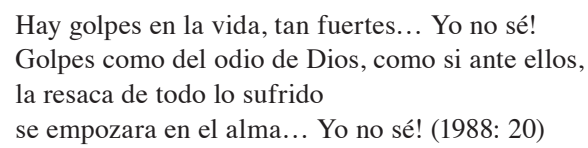

La incertidumbre que se expresa en Vallejo incide en la manera en que se percibe a la divinidad; el sufrimiento extremo se clava y cala en el alma del ser humano perforándola de dolor. Julio Fausto Fernández nos recuerda, en su ensayo sobre el origen del dolor humano, que en la base de alguna de estas teorías, Dios "es la causa eficiente y directa del dolor" (1964: 35) o, el contrario, en algunas "el dolor brota de un principio sobrenatural, diferente y antagónico a Dios" (Fernández 1964: 36), mientras plantea que otras "ven la causa de todo sufirmiento en la prevaricación del espíritu, en el mal uso que de la libertad esencial que Dios les otorgara, han hecho los demonios y los hombres" (1964: 36). A la luz de lo anterior, en la afirmación “¿Verdad que Tú no tienes/ un puñal en la mano?” (vv. 7-8) las interrogantes de Jorge Debravo nos conducen hacia esa duda existencial, si Dios es la causa del sufrimiento del ser humano. La pregunta incide en la dolorosa reflexión nocturna que se desarrolla en la noche. Debravo no afirma abiertamente en estos poemas que Dios sea la causa del dolor; tampoco nunca plantea la idea de la expulsión o la pérdida del paraíso para el ser humano. En Milagro abierto, el ser humano sufre, se le clava o perfora el alma o el cuerpo, mientras que éste recurre o increpa a la divinidad, que parece haberlo abandonado ante esta condición. Por eso, en los poemas analizados, el sufrimiento humano y, su consencuencia, el dolor, parecen ser absurdos dentro de esa conciencia "de la amargura y la desazón" (Monge 1984: 49).

Por esa razón, en la contigüidad y secuencialidad, Jorge Debravo nos pone un poema en el que la nota cromática, el negro de la oscuridad de la noche intensifica la ausencia de la divinidad dentro de un paisaje marino que reinventa los procedimientos descriptivos de la mirada especular. Tiene razón Ma. Isabel López Martínez en ver la significación del popular motivo de la "pena negra" y "su campo significativo, transmutándose en amargura por la contemplación del avance inexorable del fin de la creatividad" (1992: 129), del paso del tiempo y de ese horizonte que obliga a mirar hacia adentro de sí mismo:

\footnotetext{
Arriba el cielo negro.

Abajo el agua negra.

El muelle negro

a mis pies.

Lejos una estrella viva $\quad 5$

abre su gota de miel.

Cielo negro. Noche negra.

Agua negra...

Todo en esta noche es

de carbón:

Muelle negro.

Agua negra.

Y negro en mi alma

Dios. (30)
} 
El poema tiende a valorizar el horizonte en la oposición que establecen los dos versos iniciales con los deícticos "arriba/ abajo". Así, cielo (v. 1) y mar (v. 2) entran en una equivalencia que señala la valorización del paisaje como trasunto del estado anímico del yo lírico. Se centra, pues, en la aventura de la contemplación de la noche marina, en tanto acceso privilegiado a una significación extraordinaria y radical; por ello no nos extrañe que el punto de referencia cromático sea la negritud y la oscuridad de la noche, solamente interrumpida en su densidad por la aparición de "una estrella viva" (v. 5) en la lejanía. La repetición de los mismos lexemas "cielo", "noche" y "agua", todos calificados con el color "negro", además de producir ese ritmo cadencioso que el verso corto sabe reproducir con pertinencia, intensifica por un lado, el axis mundi propio de la contemplación del paisaje y, por otro, la apabullante oscuridad de la noche, por lo cual se transforma en un verdadero epíteto para caracterizar la significación profunda de la ausencia/ presencia que emergerá en el final sorpresivo del poema. Algo parecido sucede en el poema "Medialuz" de Los heraldos negros, en el que, centrado en el límite visual de la "fuga", los límites del cielo y del muelle se dibujan para pintar el nocturno marino y la luna se aprecia en todo su encanto de novia con sus "encajes" del cielo estrellado:

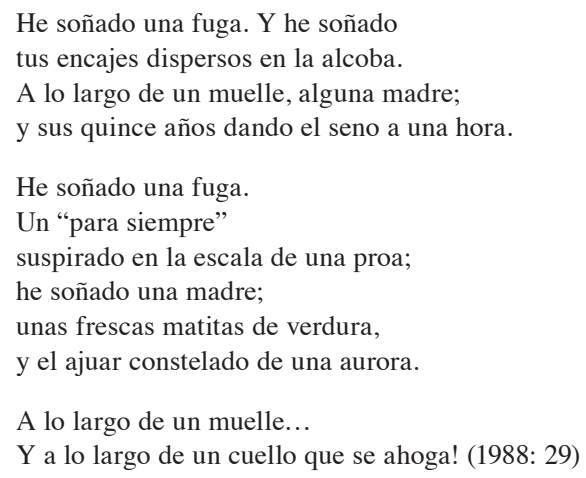

Toda la escena de contemplación ocurre desde un muelle en el poema de Vallejos; compara con la "luna" imágenes relacionadas con lo materno-femenino y el énfasis está dado en el reflejo de la especularidad del reflejo lunar en el paralelismo que establece en los dos últimos versos: la forma del "muelle" y del "cuello", meláncolicamente, se relacionan con un verbo nada inocente, "ahogar" que no sólo marca el límite de la visión, sino que también agrega una tonalidad negativa al paisaje marino descrito.

Ahora bien, regresando al poema de Debravo, observemos cómo en la arquitectónica del poema o disposición tipográfica del poema en bloques (Martínez Fernández 1996: 55), el ritmo aumenta gradualmente para que de la primera sencilla estrofa de dos versos, pasemos a la última con ocho versos, la cual es múltiplo de la segunda con cuatro versos, como si estuviera pintando con las palabras la extensión de ese "muelle" y el reflejo de luz lunar en la noche, tal y como lo realiza también Vallejo. Con ello se pasa de una máxima condensación (estrofa 1) al despliegue de su dispersión (estrofa 3), para que la mirada del paisaje se vaya profundizando y dilatando a medida que la concentración de la mirada se hace más efusiva y persistente, con lo cual el movimiento obliga a interiorizar para que ahora se despliegue la confesión absoluta del yo lírico. La sorpresa es evidente, no tanto por la asociación con el color negro, sino porque al replegarse por ese proceso dinámico de los opuestos arriba/abajo, cielo/mar, el movimiento empuja, o más bien propulsa, al yo lírico hacia su "alma" (v. 13), en donde emerge la divinidad asociada con el color negro. El valor negativo es harto evidente y subraya el sentimiento de 
carencia y de vacío, de la "ausencia oscura", en donde generalmente el mar y la noche son el marco perfecto para la despedida de los amantes, como sucede en el poema "Despedida", del poemario Belleza (en verso) ${ }^{7}$, escrito entre 1917 y 1923 por el español Juan Ramón Jiménez:

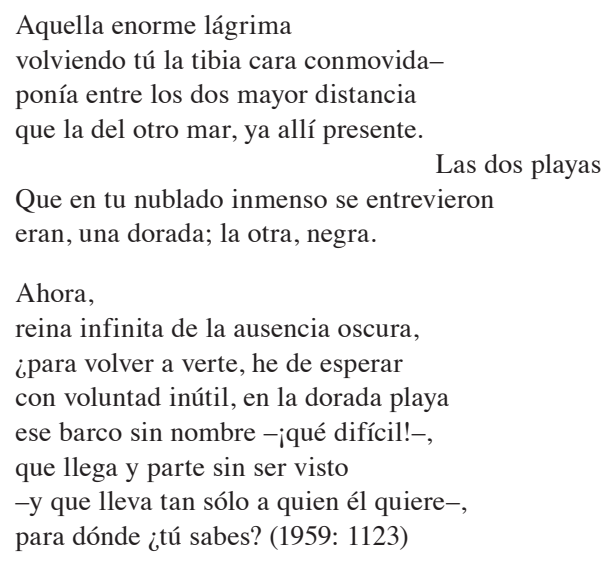

Reconocemos varios elementos presentes en "Arriba el cielo negro", propios del motivo de la "ausencia oscura", el "mar" en su metonimia "agua negra"; la "playa" también en su metonimia "arena"; la "distancia" entre magnitudes "cielo/agua" o "estrella/muelle"; pero motivos juanramonianos que permitirán establecer el enlace con el siguiente poema de Debravo, en donde aparecerá el motivo de la nave. En este sentido, el poema anterior no es el único nocturno marino en Milagro abierto. Relacionado con el motivo del naufragio, aparece un poema en el que el mar desemboca en el simbolismo del océano como un lugar del caos y de la incertidumbre (Boruchoff 2001: 856-857), de manera que la convención de la navegación azarosa y sujeta a los peligros sobrepasa tanto el entendimiento como el esfuerzo humanos, resemantizando el significado de unas aventuras, léase peripecias y avatares en los que el ser humano se enfrenta a lo indeterminado y a lo desconocido. Por eso, escuchamos el grito que muestra la zozobra ante la navegación y se pide el auxilio divino:

Arena.
Arena.
- ¿Dios?
-En el mar.
La luna se oye $\quad 5$
en el agua
chapotear.
Costas.
Costas.
- ¿Yo?
-En el mar.
Mi alma infla
su entraña
para flotar.
Dios mío.
Dios mío.
Tú y yo
juntos
en el mar. (28)


La repetición anafórica en forma de paralelismos que produce una gradación en los versos 1-2 (“Arena"), 8-9 (“Costas”) y 15-16 (“Dios mío”), o la del estribillo "en el mar”, en los versos 4, 11 y 19, conducen a un ritmo y a una musicalidad logradas en la repetición, lo cual, aunado a la simetría estróficano en pareados y tercerillos crea esa sensación de conducción reposada bajo la luna, pero que se ve interrumpida por el vocativo de los versos 15-16 ("Dios mío"), cuando de repente se entra la zozobra del alejamiento de las costas. De esta manera, los dos puntos que muestran el rumbo y el movimiento, como si fueran mojones es "Arena" (el punto más cercano) y "Costa" (el punto más lejano), que despliega el motivo de la travesía marina, aparecen bajo el tópico del mar tempestuoso. Debravo retoma la metáfora naútica que, desde la Antigüedad grecolatina, se relacionará con la técnica de la navegación y el dominio que debe tener el marino para soltear sus peligros y llegar a buen puerto. Recordemos con Luc Torres (2009) que se trata de esa metáfora acuática "de la navigation comme symbole de la traversée de la vie terrestre" (Torres 2009: 110), es decir, "comme métaphore de la traversée de la vie" (Torres 2009: 99). Llegar a buen puerto y sortear las inclemencias del mar son aquí los dos motivos de esta búsqueda iniciática que el ser humano emprende, pero que se ven resemantizados por esa metaforización del ser humano como una nave que se dirige, o a puerto seguro o a puerto incierto, según la concepción que se presente en la visión de mundo del poeta. Ahora bien, en el poema de Debravo, la sinécdoque "Mi alma infla/ su entraña/ para flotar" (vv. 12-14) devela esta metaforización del yo lírico, ahora convertido en nave que despliega sus velas hacia el horizonte en el que la luna marca el rumbo de la travesía sino también la guía: "La luna se oye/ en el agua/ chapotear" (vv. 5-7). El acompañamiento de la divinidad es evidente en la sensación de seguridad que la travesía ahora supone, por lo cual se subraya la certidumbre de que el viaje ya no representará ningún peligro para quien lo emprenda.

Queda claro, a partir de los poemas analizados hasta aquí, que en el curso de la experiencia humana, la divinidad se puede hacer presente y que, en Jorge Debravo, el poeta nos presentará, en Milagro abierto, ese proceso en el que la condición del ser humano, matizada por la experiencia del dolor y de la tragedia humana, increpará a la divinidad y preguntará con vehemencia tanto sobre su presencia en la realidad humana, imperfecta y azarosa, como sobre el accionar de la trascendencia en su devenir ${ }^{8}$. El nocturno debraviano, en ese tránsito meditativo y al calor de una temporalidad iluminada por la sensualidad de la noche, conducirá hacia meditación en que el reloj, la candela (el fuego) o la lumbre, serán los motivos desencadenantes de la meditación, lo que no es casual en lo que Béguin ve como el umbral de la "noche romántica" en el que la habitación solitaria y los objetos que están ahí, lo más común, los libros y la "candela encendida", activan el "progreso interior y soñador" (Béguin 1993: 45):

\footnotetext{
La noche me cae en el alma.

Como una humareda

se me mete en los poros.

La noche está aquí al lado

desnuda sobre mi lecho

como una negra desnuda.

La noche me entra en la boca.

Mis labios la saborean

como un vaso de café.

La noche es como Dios: grande.

$¿ \mathrm{O}$ es Dios este gran chorro

de carbón y de alquitrán? (29) 
Poema sencillo de una simetría estrófica con versos octosílabos en tercerillos, con una repetición anafórica de "La noche" en posición inicial en todas las estrofas, Jorge Debravo demuestra otra vez su apuesta por el ritmo interno y la musicalidad reposada. De esta manera, los elementos expresivos se motivan para subrayar el motivo de la noche iluminada del amante/filosófico entusiasta y reflexivo. Ya nos recuerda Miriam Hoffmann, analizando el caso del poeta español Antonio Machado, que no se le acordado "la debida importancia al concepto de la 'otredad' del ser" (1964: 339), a la hora de plantear el sentimiento y necesidad de Dios, ya que toda su búsqueda desemboca en un proceso autorreflexivo. El proceso de ensimismamiento se anuncia en el verso 1 ("La noche me cae en el alma") para que se logre esa introspección necesaria en la que el yo lírico interroga a la divinidad. Observemos que la noche se personifica y la escena doméstica a la que asistimos en la del lecho de los amantes, como si la noche viniera a su cita amorosa, con el fin de que la penetración, al contacto de lo táctil, se anuncie en las siguientes acciones:

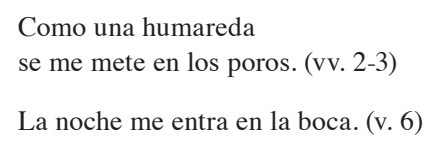

Así, en la unión/efusión amorosa dominarán dos elementos, los cuales desencadenan el motivo del fuego y se expresarán en el último cuarteto en las metonimias "gran chorro/ de carbón y de alquitrán" (vv. 11-12), con lo cual se subraya el estímulo de lo calórico/magnético; se trata de una gran sensibilidad a los cambios de temperatura (González Durán 1990: 31). La cocina y la lámpara hacen su aparición para que esa luz, calurosa pero también efímera de la "candela" romántica haga su aparición y se relacione con la presencia de la divinidad. La pregunta expresa aquí no solo la emoción sino también el asombro que no se puede contener de lo que, en este contexto, es "milagro" ostensible de este momento único y perfecto. Verdadera teofanía, la divinidad se asocia aquí con ese "vaso de café", en una imagen en la que el gusto por sorber se asocia a esa piel que siente el calor del fuego"; "vaso de café" que se degusta con deleite en una noche que invita a la comunión, logrando eso que desea en toda buena poesía, que lo sugestivo nos conduzca a la "emoción convertida en imagen" (Ernest Cassirer citado por Castilla del Pino 2000: 68), dentro de una visión nocturna que obedece a la dulce nostalgia de la sensualidad de la noche.

La cuestión de la divinidad, capital en los primeros libros de Jorge Debravo como pueden ser Milagro abierto o Canciones cotidianas (tal y como veremos en otro futuro trabajo ${ }^{10}$ dan cuenta de ese doble movimiento propio de una experiencia de lo sagrado, interiorizar/trascender, por lo que "el punto de llegada, en la búsqueda del ser, de la verdad y de la maduración interior, podría expresarse como una interioridad trascendida" (Carravilla Parra 2008: 95). La noche y el silencio de la soledad que ella desencadena son los motores de tal experiencia que, con imperiosa necesidad, embarga al yo lírico en estos poemas analizados; su intención es clarificadora; sus palabras desgarradoras porque la divinidad no se manifiesta al individuo plagado de dudas y de interrogantes. Siempre se ha analizado el fenómeno de la mística como un regreso a la interioridad reflexiva del creyente, pero en Jorge Debravo, la escucha y la palabra pronunciada desembocan más bien en esa distancia y en una ausencia de respuesta que no parece traer ni sosiego ni tranquilidad; generan más dudas y silencios, nada positivos, pues significarían, que la persona interrumpe la palabra o hay ausencia de ella ${ }^{11}$. Por eso, en su búsqueda de la divinidad, en Milagro abierto el yo lírico continúa golpeándose 
y exorcizando esa comunicación que intenta trascender y salir de una interioridad ansiosa de comunión con una escritura poética que busca la luz en la oscuridad de la noche. Ramiro Flórez se hace la misma pregunta desde la lectura que hace Martín Heidegger acerca de la experiencia de Dios en San Agustín y retoma en este punto a Heidegger, el cual citamos porque está aquí explícito lo que a Debravo tanto angustia:

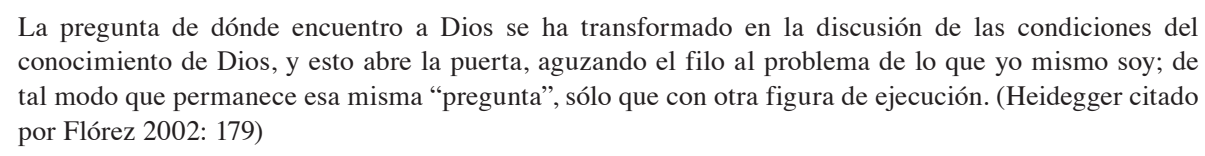

La pregunta de dónde encuentro a Dios se ha transformado en la discusión de las condiciones del conocimiento de Dios, y esto abre la puerta, aguzando el filo al problema de lo que yo mismo soy; de tal modo que permanece esa misma "pregunta", sólo que con otra figura de ejecución. (Heidegger citado por Flórez 2002: 179)

La clave o la estrategia no es saber oír la voz de la divinidad o saber comprender sus formas de presencia (como dice el proverbio: "los caminos de Dios son inescrutables), sino en saber experimentarlo en la noche oscura, tremenda y melancólica. Los grandes poetas han sabido dar esa respuesta sincera a la que la noche, ensimismada y callada, obliga a la reflexión meditada y pausada. Es lo que sucede en Milagro abierto, en tanto posibilidad de que la iluminación y la humanidad propulsen al ser humano hacia un diálogo abierto y receptivo.

\section{Notas}

1. Este es un avance del proyecto inscrito en el CIICLA con el título de "La poesía de Jorge Debravo y su modelo comunicativo: la súplica poética”.

2. En efecto, veamos del poema de San Juan de la Cruz, que estoy parafraseando, la estrofa inicial: "En una noche oscura/ con ansias de amores inflamada/ joh dichossa ventura!/ salí sin ser notada/ estando ya mi casa sosegada" (1982: 150).

3. Si no hay indicación, en lo sucesivo los poemas analizados pertenecen a esta sección del poemario.

4. La reminiscencia es un poco lejana con el "Romance de la luna, luna".

5. "La coherencia de este sistema simbólico lleva a comprender que la belleza plasmada en la luna, foco de luz en la oscuridad se relaciona con el rayo de inspiración persistente cuando la mente se nubla" (1992: 128) y se desencadena los procesos introspectivos.

6. Veamos lo que reconoce el poeta Ronald Bonilla, compañero de generación, en la entrevista otorgada a Magda Ma. Brenes Papayorgo: "habría que ver esa escuela no es Debravo, viene de antes, de otros poetas y otras latitudes: Hernández, Vallejo, que es muy importante en la poesía de Debravo” (263).

7. El ejemplo lo introduce López Martínez para abordar efectivamente el motivo de la "ausencia oscura" (164).

8. Cabe anotar que en su fundamental estudio Yadira Calvo estudia como poesía religiosa el largo poema "Consejos para Cristo al comenzar el año", que pertenece también al poemario Milagro abierto; y al respecto apunta: Todos los poemas de este libro están concebidos bajo la actitud conocida como 'apóstrofe lírico', de donde proviene el efecto dramático que se percibe en él. Se supone un diálogo con Cristo a diferentes niveles de acercamiento, desde el simple intercambio de fórmulas de cortesía hasta la misma deprecación" (1980:152). Además, "la figura de Cristo se desdiviniza, es presentado en sus dimensiones más humanas" (1980: 158), pero no sería el caso de la figura de la divinidad. 
9. No es casual esta asociación entre lo tactil y lo gustativo, Roxana González Durán, pondera tales asociaciones en la percepción de los sentidos en su tesis sobre el poemario Vórtices (1990: 75-83).

10. Y no lo estamos pensando en una perspectiva biográfica sino textual; lo es de esta manera porque abandona en su posterior poesía interrogaciones a la divinidad, centrándose en la figura de Cristo más bien, con referencias explícitas a una teología de la liberación.

11. A este respecto, Sara Gallardo González nos recuerda las dos acepciones de silencio en latín: "El latín distingue dos formas de silencio: tacere es un verbo activo, cuyo sujeto es una persona, que significa interrupción o ausencia de palabra: silere es un verbo intransitivo, que no sólo se aplica al hombre sino también a la naturaleza, a los objetos o a los animales, y que expresa la tranquilidad, una presencia apasible que ningún ruido interrumpe" (158, las cursivas son del texto). Efectivamente, el yo lírico se calla, pero el silencio reposado o sosegado no lo posee.

\section{Bibliografía}

Abrams, M. H. s. f. El espejo y la lámpara: Teoría romántica y tradición clásica acerca del hecho literario. Buenos Aires: Editorial Nova.

1992. El Romanticismo: Tradición y revolución. Madrid: Editorial Visor.

Aguiar e Silva, Vítor Manuel. 1979. Teoría de la literatura. (3 ${ }^{\text {era }}$ reimpresión). Madrid: Editorial Gredos.

Alonso, Dámaso. 1981. Poesía española: Ensayo de métodos y límites estilísticos. (3 ${ }^{\text {era }}$ reimpresión). Madrid: Editorial Gredos.

Béguin, Albert. 1993. El alma romántica y el sueño: Ensayo sobre el romanticismo alemán y la poesía francesa. ( $2^{\text {nda }}$ Reimpresión). Madrid: Fondo de Cultura Económica.

Bernat-Vistarini, Antonio (Ed.). 2001. Actas del IV Congreso de la Asociación de Cervantistas. Tomo II. Palma de Mallorca: Servei de Publicacions de l'Universitat de les Illes Balears.

Brenes Papayorgo, Magda. 1990. Jorge Debravo: legitimación y permanencia. Tesis de Maestría en Literatura Latinoamericana: Universidad de Costa Rica.

Boruchoff, David A. 2001. "Persiles y la poética de la salvación cristiana”. En: Bernat-Vistarini (ed.), 853-874.

Bridges, Christine M. E. 1999. "La primera manifestación de la poesía femenina: la canción de cuna". Letras Femeninas. 25 (1-2): 107-113.

Calvo, Yadira. 1980. Poesía en Jorge Debravo. San José: Ministerio de Cultura, Juventud y Deportes. 
Carravilla Parra, Ma. Jesús. 2008. “Interioridad trascendida en Ramiro Flórez”. Cuadernos del Pensamiento. 21: 95-118.

Castilla del Pino, Carlos. 2000. Teoría de los sentimientos. (3 ${ }^{\text {era }}$ ed.). Barcelona: Tusquets Editores.

Debravo, Jorge. 1994. Milagro abierto. (5 ${ }^{\text {ta }}$ ed.). San José: Editorial Costa Rica.

Delpech, François (ed.). 2009. L’imaginaire des espaces acuatiques en Espagne et au Portugal. París: Presses Sorbonne Nouvelle.

Fernández, Julio Fausto. 1964. Radiografías del dolor: Origen y proyecciones espirituales del sufrimiento. San Salvador: Ministerio de Educación Pública.

Flórez, Ramiro. 2002. “El 'cogitare divina' de San Agustín en Heidegger”. Cuadernos del Pensamiento. 15: 171-200.

García Lorca. 1991. Primer romancero gitano. Edición de Christian de Paepe. Madrid: Editorial Espasa Calpe.

Gallardo González, Sara. 2008. “El silencio como atmósfera de la persona”. Cuadernos del Pensamiento. 21: 157-174.

González Durán, Roxana. 1990. Análisis semántico-estructural y estilístico del libro de poemas "Vórtices" de Jorge Debravo. Tesis de Licenciatura en Filología Española: Universidad de Costa Rica.

Hernández, Miguel. 2002. El rayo que no cesa. (Edición de José María Balcells). Madrid: SIAL Ediciones.

Hoffmann de Gabor, Miriam. 1964. "El Dios de Antonio Machado". Revista de Filosofía de la Universidad de Costa Rica. 4 (15-16): 339-345.

Jiménez, Juan Ramón. 1959. Libros de poesía. Tomo I. (Edición de Agustín Caballero). (2 $2^{\text {da }}$ ed.). Madrid: Ediciones Aguilar.

Juan de la Cruz, San. 1982. Obra poética. (Edición de Miguel de Santiago). Sant Cugat del Valles: Libros Río Nuevo.

López Martínez, Ma. Isabel. 1992. La poesía popular en la obra de Juan Ramón Jiménez. Sevilla: Diputación Provincial.

Martínez Fernández, José Enrique. (1996). El fragmentarismo poético contemporáneo (Fundamentos teórico-críticos). León: Servicio de Publicaciones de la Universidad. 
Monge, Carlos Francisco. 1984. La imagen separada: Modelos ideológicos de la poesía costarricense 1950-1980. San José: Instituto del Libro.

Torres, Luc. 2009. "Boussole à l'usage des navigateurs du frontispice marin de La Pícara Justina”. En: Delpech (ed.): 99-114.

Vallejo, César. 1988. Obra poética. (Edición de Américo Ferrari). Madrid: Colección Archivos. 